Thus when applying Bailliart's method, the pulse of any other artery must be examined simultaneously, and the moment of reversal of the rhythm is to be regarded as the indication of minimal pressure. The difference between systolic and diastolic pressure in the central retinal artery will then be much smaller and will no doubt correspond with the actual state of affairs. Taking into account that in the off-branchings of the central artery rebounding movements are usually accentuated only very slightly, we may assume that the differences in pressure in these arteries will also be very small. It is of no special importance to which artery the measurements by Bailliart's method are applied, as the results can be only relative, although their clinical value will be indisputable.

I believe that the application of this modification of Bailliart's method in determining the indicator will help to eliminate to a considerable extent the disparities. in the results obtained by various authors.

\title{
BIBLIOGRAPHY
}

BECKER, O.-Graefe's Arch.f. Ophthal., Vol. XVIII, 1872.

HoRst, A.-Problems of Haemodynamics, Bulletin de la Sociéte des Amis des Sciences de Poznan, Série B, Livraison VIII, 1947.

\section{A CASE OF PIGMENTED LEIOMYOMA OF THE IRIS}

\author{
BY \\ NoRman Fleming
}

LONDON

Mrs. S. consulted me on August 15, 1944, with regard to something wrong with her left eye. This proved to be a tumour, involving apparently the whole breadth of the iris and extending over the lower and inner third of its circumference. The growth was encroaching on the pupil, rendering the pupillary margin convex instead of concave in the part involved. In shape the tumour was like a bean and in colour purplish black. The surface was smooth and the margins clearly defined. The growth was in contact with the cornea for about a quarter of its extent and some secondary change in the cornea could be made out.

The patient complained that this mass was increasing in size and becoming dark in colour, that her sight was not so good and that the eye was diverging. This change had been noticed during the past year. The patient's own story leaves one in no doubt 
that before that time a swelling of the iris had been present for many years, but the colour had been much the same as that of the rest of the iris. Quite recently I have heard through the patient's father that her mother, who died aged thirty-three when the patient was a baby, had something wrong with one iris, which in his opinion resembled that seen by him in the patient's eye when she was a child.

The growth was so sharply defined that I decided to endeavour to remove it without removing the eye. A conjunctival flap was turned down corresponding to the position of the tumour and an incision, concentric with the limbus and extending for one-third of the circumference, was made in the sclerotic with a Graefe knife. Through this incision, the iris was withdrawn at one end of the tumour, the iris divided, the tumour delivered, and the iris again divided on the other side of the growth. The conjunctival flap was then replaced and stitched. The operation having been successfully performed, the eye healed without any complications.

I have seen Mrs. S. this month (March, 1947). The eye is quiet, corrected vision is $6 / 5$ right and left and she is in the best of health.

The case reported was at first thought to be a malignant melanoma of the iris, but in view of the smoothness of the outline of the tumour and the absence of any evidence of invasion of other tissues, I was in doubt as to whether she should be subjected to deep X-ray treatment or not. I asked Dr. Douglas Webster for his opinion and we decided to ask the opinion of Professor Scarff, Bland-Sutton Institute of the Middlesex Hospital. He reported as follows :-

"I do not think that the appearances indicate melanoma, but rather the tumour usually referred to as leiomyoma of the iris, with included pigment granules."

In addition to expressing my thanks for his report, I have to record my indebtedness to Professor Scarff for the excellent microphotographs.

No further treatment was undertaken.

There is little to be found in the literature about this very rare tumour and the following résumé is, I think, fairly comprehensive.

In 1898, A. H. Thompson showed a case of Lawford's, a small pinkish cauliflower-like growth of the iris. This was later removed and diagnosed as a spindle-celled sarcoma by all save John Griffith, who contended it was a myoma of the iris and probably a unique growth in that region. It was apparently free from pigment. A drawing of the microscopic structure of the growth is published with the paper which shows clearly that it has much in common with the case here described and with that of Verhoeff.

Only three cases definitely accepted as leiomyomata are 


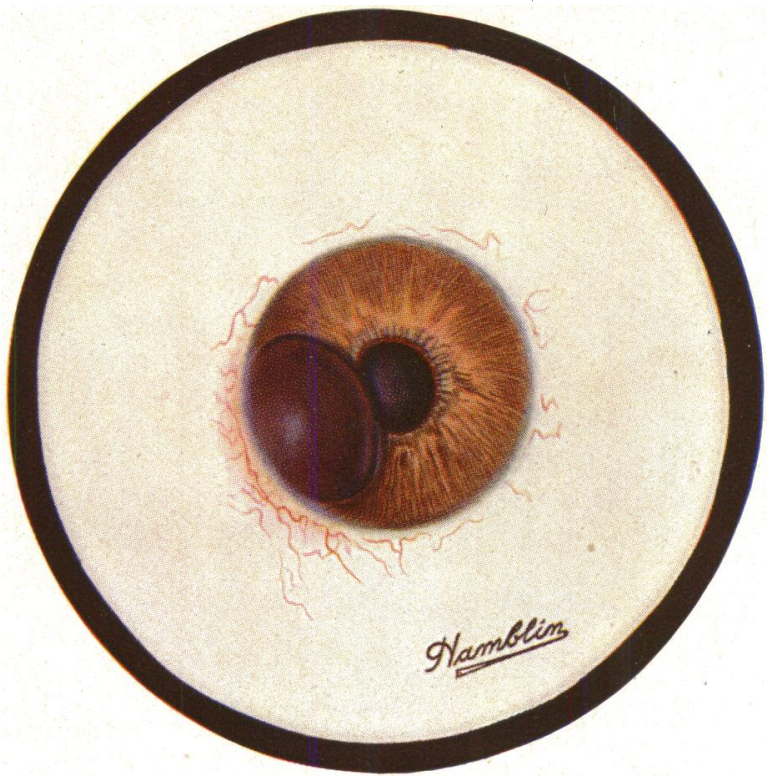

Picture 1.

Appearance of the eye before removal of growth.

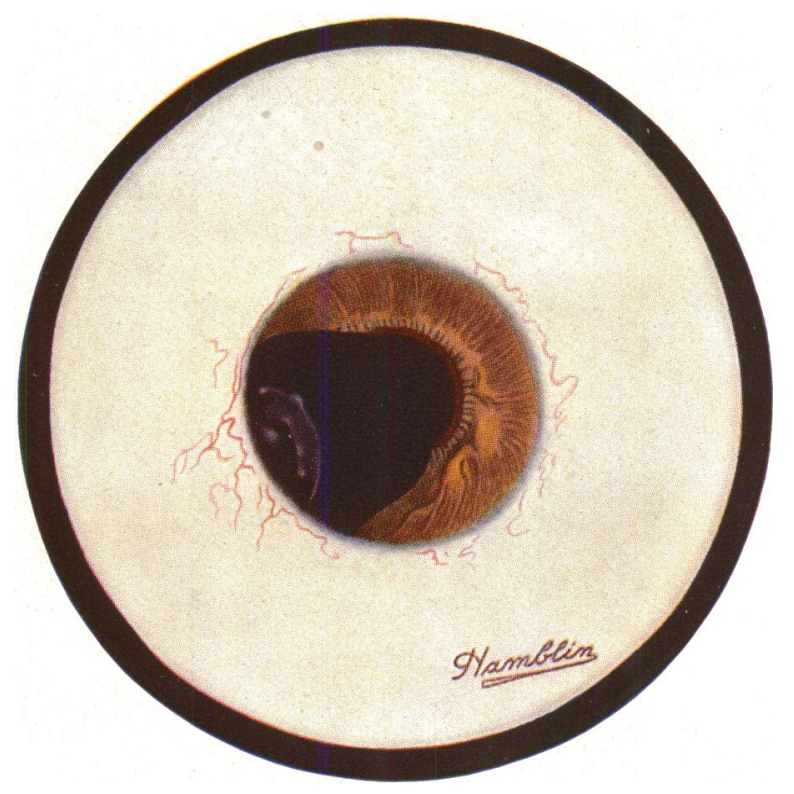

Picture 2.

Appearance of the eye after removal of growth. 
recorded. The first is that of Verhoeff, published in 1923; and described by him as a case of mesoblastic leiomyama of the iris. He states: "the general character of the cells as shown by ordinary stains, together with the presence of myoglial fibrils, leave no doubt that the tumour was a myoma." An unsuccessful attempt to remove it by iridectomy was made in 1904, but a fragment of the tumour, sufficient for microscopical examination; was excised. A second attempt was made in March, 1920, when several fragments of tumour tissue were removed and examined; subsequent enuoleation was necessary two months later.

The growth as seen before operation was pinkish in colour. Microscopically tumour cells showed no mitoses; a few branched chromatophores were present near the blood vessels. After sixteen years it did not invade the iris stroma nor did it involve the filtration angle. It arose from the anterior surface of the iris.

The microscopic structure of this growth also is illustrated.

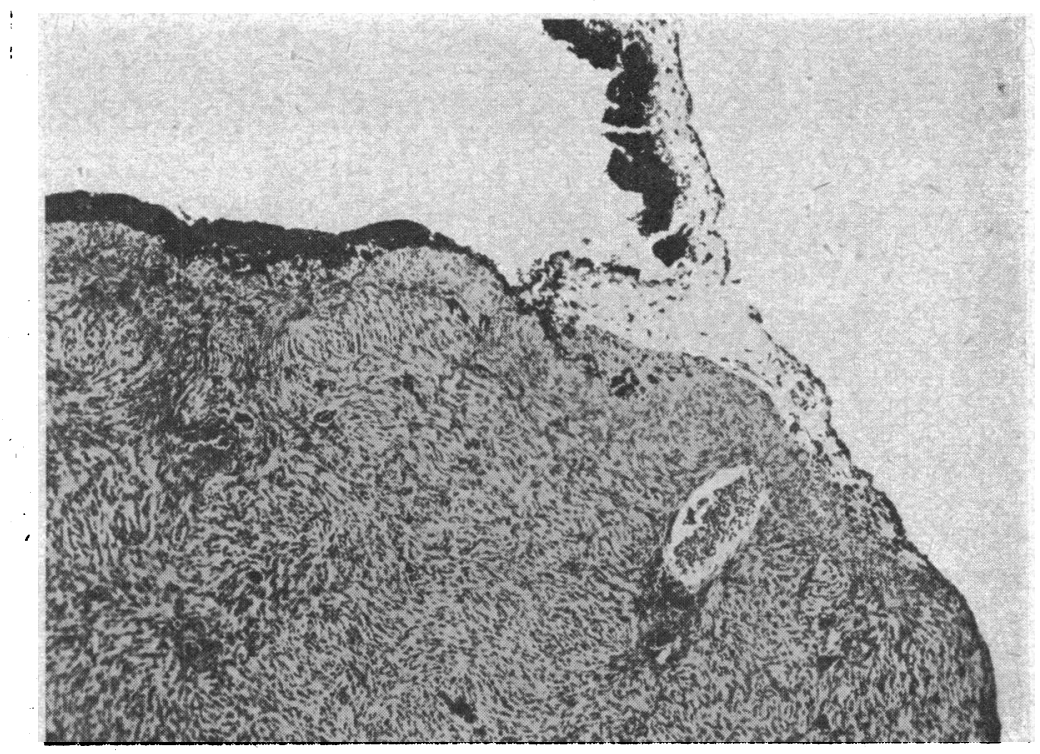

FIG. 1.

Section of the growth magnified $\times 60$.

The second case is that of A. D. Frost, published in 1936. There was a history of two years only. This tumour was yellowish-grey in colour with ectropion of the uveal pigment; it was sessile, and half the width of the iris; the surface near the pupillary border was dotted with pigment. The eye was removed. The growth was 


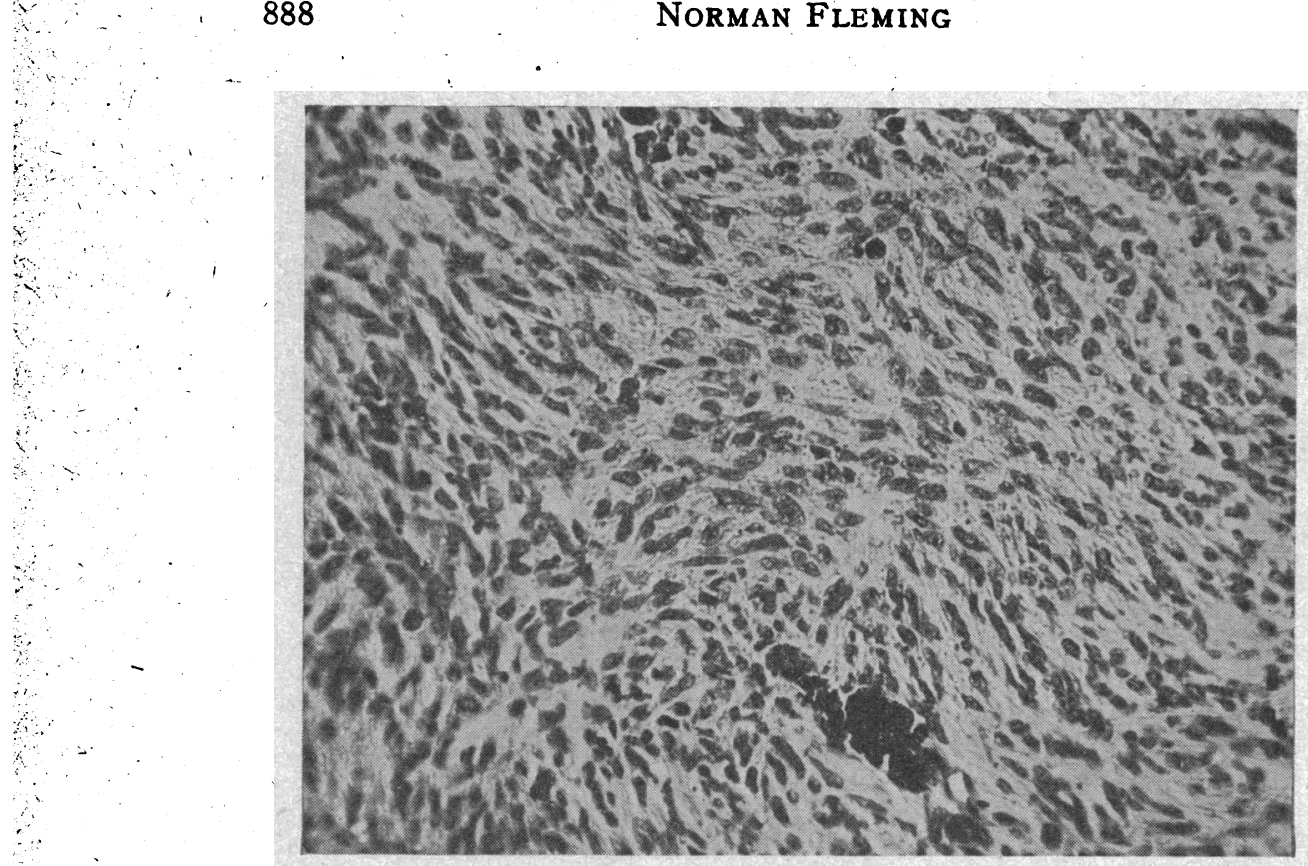

FIG. 2.

- Section of the growth magnified $\times 275$.

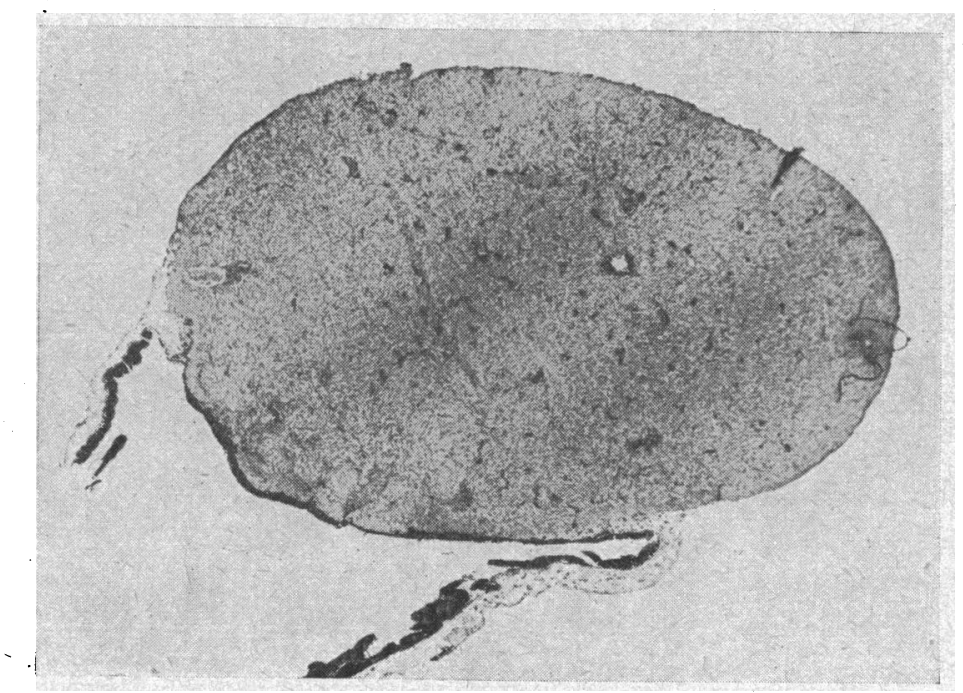

Fig. 3.

Section of the growth magnified $\times 17$. 
not pigmented, but a few scattered chromatophores were seen. There were no mitoses. Like Verhoeff, Frost also obtained differential staining with Mallory's phosphotungstic haematoxylin and demonstrates myoglial fibrils by gold impregnation. He comments: "Its outstanding pathologic characteristics include a structure of interlacing closely packed bundles of spindle cells with rod-shaped nuclei in palisade arrangement, displaying eosinophilic cytoplasm and myoglia fibrils."

In Ellett's case in a man of 47 the presence of the tumour had been noted for fifteen years and the iris to have been elongated vertically for five years before that. There is nothing to indicate that the two abnormalities had more than a fortuitous association. It is described as having been light in colour but becoming darker. The eye was enucleated, however, and the growth found to be unpigmented.

It was removed as a sarcoma but diagnosed by Verhoeff as an epiblastic leiomyoma. Verhoeff now considers that the growth arises from the neural epithelium just as does the dilator muscle. He described his case as a mesoblastic leiomyoma in 1923, two year before the publication of Collins and Mayou's Pathology, where it is pointed out that the fibres of the two iris muscles arise from the neural epiblast, whereas the ciliary muscles are mesoblastic in origin.

It would appear that in the case described in the present communication, the tumour was very much larger than in any of the other three; it is unique in that it was heavily pigmented and in that the father's description of her mother's eye strongly suggests a hereditary factor. In the doubtful case of Thompson, the growth was removed by iridectomy by Lawford, but in all three accepted cases the eye was enucleated.

$\mathrm{Mr}$. T. H. C. Benians, who was very interested in this tumour, has kindly given me the following commentary :-

"The four published cases of this condition that may be considered histologically established (i.e., Thompson, Verhoeff, Frost and Ellett), were all in the lower half of the eye, and the same is true of the present case."

From the descriptions and illustrations now available of these five cases there seem to be two types.

In Frost's and Ellett's cases, the growth extends diffusely through almost the whole width (and in Ellett's case the whole depth) of the iris, and the sphincter muscle is involved in both cases. In the other three the tumour projects. Thompson's is described as cauliflower-like. Verhoeff's was attached by a narrow band to the anterior surface of the iris, and in the present case a more or less spherical tumour has its narrow posterior zone sunk 
in the substance of the iris. The two last growths definitely have no relation to the sphincter muscle and Verhoeff's appears to rise direct from the anterior pigment layer which constitutes the dilator muscle.

In considering this growth of which only sections were available, I had the advantage of discussing it with Dr. W. M. Woods and we felt that the possibility of it being an unusual form of leiomyoma should not be disregarded. The sections show a piece of iris containing an almost spherical neoplasm $(0.4 \times 0.3 \mathrm{~cm}$.) which has a very well defined border. A small posterior zone of the neoplasm has replaced both the vessel layer and the anterior border layer of the iris at the site of the neoplasm, so that here only the posterior pigment layer of the iris remains and forms a capsule for the neoplasm posteriorly. The greater part of the neoplasm bulges anteriorly from the iris; its anterior and lateral surfaces are smooth, but show neither capsule nor covering cells. The tumour has a very uniform structure throughout. It is composed of spindle cells, with spindle nuclei and moderately long cytoplasmic bodies. There is very little variation in the morphology of the nuolei and cytoplasm. There is a little imperfect palisading of nuclei. The cells are arranged in a conspicuous regular pattern of bundles; the central cells of each bundle tend to be parallel to one another, while the peripheral cells are curved so that their ends are approximated at opposite poles of the bundle. This is a pattern that is commonly seen in neuro-fibromata, and is quite different from the pattern of leiomyoma of skin or uterus, where all the cells of each bundle are parallel to one another and the bundles are interwoven, so that in any section some bundles show all cells cut longitudinally and others show all cells cut transversely. The cells are not so broad, they have not so much cytoplasm, as the cells of the common pure leiomyoma of the skin, but they contain numerous thick glial fibres, which are characteristic of leiomyoma, but are usually absent from the cells of neuro-fibroma (schwannoma).

Therefore, this tumour has one structural feature that is found in neuro-fibroma and another that is found in leiomyoma. There is much pigment throughout the tumour, but it is mostly in dense clumps and would appear to be some of the normal pigment of the iris included in the tumour tissue, some of it being also in stellate form suggesting its presence in macrophages. Some of the pigment seems to be present in a few of the tumour cells and therefore it may seem justifiable to regard the tumour as a melanotic neuroectodermal leiomyoma.

Since one must have a fixed point it might be said first that the presence of myoglial fibres, very clearly demonstrated by Mallory's 
phosphotungstic acid-haematoxylin, entitles it definitely to be classified as a leiomyoma. This point is stressed by Verhoeff in relation to two of the three cases he has seen. The general structure of the growth on the other hand has more in common with a neurofibroma (schwannoma) than with the ordinary mesodermal leiomyoma and it is to be noted that Verhoeff in two of the cases he has examined draws attention to the palisading of nuclei, a feature very characteristic of schwannoma, though it also occurs sometimes in leiomyoma of the uterus. As to pigment in the four cases already published, and referred to above, pigment appears to have been very scanty and what there was was apparently present in macrophages only so that the question of melanoma did not arise. In the present case, though pigment is very abundant in perivascular spaces, its presence can only be demonstrated in a few of the tumour cells. A somewhat similar picture may be seen in some pigmented neuro-fibromas, where intrinsic pigmentation of tumour cells may be scanty.

Finally, as to the source of such growths. Both sphincter and. dilator muscles of the iris have a neuro-ectodermal origin. The sphincter, however, is fully differentiated into muscle bundles, is entirely unpigmented and could presumably give rise to a leiomyoma of classical type. The dilator muscle consists only in a partial differentiation of the outer aspect of the cells forming the anterior of the two pigmented layers covering the back of the iris. A myoma arising from such a source might not unreasonably be expected to show features linking both nervous and muscular characters, and such a mixture of characters does seem to be present in the tumour here described. A likely ectodermal character in such a growth would also be the intrinsic production of pigment and that appears to be occurring in this case though it definitely was not a feature of the other published cases. It is to be noted that Reese (1947) classifies leiomyoma of iris as a pigmented tumour.

To sum up what has been said, we felt that this group should not be classified off hand as leiomyoma of neuro-ectodermal muscle but the point should be kept open as to whether this tumour and some others, such as that of Verhoeff, do not present characters that make their classification as leiomyoma as anomalous as that of the neuro-ectodermal musculature from which they appear to derive.

Muscular and pigmentary functions co-exist in the dilator muscle cells and it might be that further degrees of muscular differentiation, corresponding to that seen in the sphincter iridis muscle, would definitely exclude the melanoblastic function. A failure in the specific myoglial differentiation in a growth from this source 
could lead to the production of a spindle celled melanoma and no doubt the question of malignancy would be closely bound up with these types of differentiation."

\section{BIBLIOGRAPHY}

Ellett, E. C. (1939).-Arch. of Ophthal., Vol. XXI, No. 3, p. 497.

Frost, A. D. (1936).-Trans. Amer. Ophthal. Soc., Vol. XXXIV, p. 86.

REESE, A. B. (1947) -Amer. Jl. of Ophthal., Vol XXX, No 5, p. 37.

Tном PSON, A. H. (1899).-Trans. Ophthal. Soc. U.K., Vol. XIX, p. 19.

VERHOEFF, F. H. (1923).-A rch. of Ophthal., Vol. LII,. No. 2, p 132.

\section{OBSERVATIONS ON EXPERIMENTAL PNEUMO- COCCAL INFECTION OF THE RABBIT'S CORNEA AND ON THEIR TREATMENT WITH' PENICILLIN*}

BY

J. MACASKiLl and M. WeAtheRALL

EDINBURGH

THE experimental production of infected lesions of the rabbit's cornea by intra-corneal inoculation of suspensions of pneumococci has been described by Ginsberg and Kaufman (1913) and by Robson and Scott $(1943 a, b)$. Cole, Hamilton-Paterson and Sorsby (1945) were unable to confirm the findings of Robson and Scott, although they used the same strain of pneumococcus. This divergence of results has not, as far as we know, been explained (Fraser, Robson, Scott and Scott, 1945 ; Sorsby, 1946). The present paper reports further observations on the lesions produced by intra-corneal inoculation of the same and other strains of pneumococci and on the effect of penicillin administered subconjunctivally on these lesions. It is by now well known that bacteriostatic concentrations of penicillin can be produced in the aqueous and cornea by subconjunctival injection of suitable doses (Andrews, 1947; Leopold and La Motte, 1945 ; Sorsby and Ungar, 1947; Struble and Bellows, 1944; von Sallmann, 1945). The present observations are directed to show whether this route of administration is in fact as well as in expectation therapeutically efficient, and if so, under what conditions.

\section{Methods}

Young rabbits of both sexes weighing 1.0 to $1.8 \mathrm{~kg}$. were used. Intra-corneal injections were performed as described by Robson

\footnotetext{
- From the Department of Pharmacology, University of Edinburgh. Received for publication, September 11, 1948.
} 